\title{
ПРАВОВОЕ РЕГУЛИРОВАНИЕ КАССОВОГО ИСПОЛНЕНИЯ БЮДЖЕТА
}

Аннотация: Исполнение бюджета это сложный многоступенчатый прочесс. Сегодня мы наблюдаем, что вся информация, вся деятельность концентрируется в органах Федерального казначейства. Это полностью отражает суть проведенной реформы. Кассовое обслуживание федерального бюджета является одним из основных направлений деятельности Федерального Казначейства, именно там происходят постоянные изменения, связанные с разработкой и внедрением элементов управления ликвидностью единого счета федерального бюджета. Целью такой работы является создание условий для более качественного и эффективного управления бюджетными средствами, направленного на обеспечение безусловного исполнения денежных обязательств федерального бюджета по мере наступления сроков платежей по ним. Выбор кассового обслуживания исполнения бюджета имеет ряд преимуществ, касающихся организачии бюджетного прочесса: во-первых, в связи с тем, что личевые счета открываются в органах Федерального казначейства и взаимодействие получателей средств осуцествляется непосредственно с органами казначейства, время исполнения платежсных документов на оплату бюджетных обязательств сокращается; во-вторых, сокращается время получения ответной информачии об операчиях, отраженных на личевых счетах получателей бюджетных средсть, что позволяет им оперативнее принимать управленческие решения; в третьих сохранение за финансовыми (уполномоченныли) органами полномочий по принятию реиений о финансировании тех или иных бюджетных расходов в условиях освобождения от технических функций по исполнению бюджета (в части открытия и ведения лицевых счетов) способствует повыиению самостоятельности бюджетов и эффективности управления бюджетными средствами. Вариант кассового обслуживания исполнения бюджетов с открытием личевых счетов главным распорядителям, распорядителям и получателям средств и доведением до них лимитов бюджетных обязательств и объемов финансирования является наиболее эффективным, но только в условиях максимального использования системы электронного документооборота. Одной из основных функиий, выполняемой органами Федерального казначейства, сегодня является учет поступлений в бюджетную систему и распределение этих поступлений по соответствующим бюджетам бюджетной системы.

Ключевые слова: кассовое исполнение бюджета, Федеральное казначейство, принцип единства кассы, ликвидноть единого счета, бюджетная система, бюджетный прочесс, банковская система исполнения, казначейская система, единый счет бюджета, кассовые выплатьл

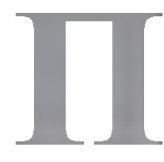
ринцип единства кассы является специальным принципом для стадии исполнения бюджета бюджетного процесса. В то же время единство кассы тесно связано с таким принципом построения бюджетной системы, как принцип единства бюджетной системы. Можно сказать, что через единство кассы в числе прочего реализуется единство бюджетной системы.

Согласно принципу единства кассы кассовое исполнение бюджета должно быть сосредоточено в одном центральном органе. При этом учреждения не вправе задерживать у себя бюджетные средства и производить из них ка- 
кие-либо расходы. Они обязаны перечислять их в тот кассовый орган, который исполняет данный бюджет.

Исторически сложилось две системы исполнения бюджетов - казначейская и банковская системы. До конца 1992 года в Российской Федерации была принята банковская система исполнения федерального бюджета ${ }^{1}$. Казначейская система исполнения бюджета выступает как, безусловно, альтернативная банковскому исполнению бюджетов.

Система казначейства обеспечивает:

a) единство нормативно-методической базы исполнения бюджета, т. е. исполнение бюджета возложено на единый государственный орган, все операции, выполняемые в процессе исполнения бюджета, регламентируются одним пакетом внутриведомственных инструкций;

б) целостность процессов исполнения бюджета (полный бухгалтерский учет операций со средствами бюджета; единую систему балансовых счетов; прогнозирование исполнения бюджета; единый бюджетный учет; централизованную обработку платежей);

в) эффективную работу по управлению бюджетными средствами ${ }^{2}$.

На органы Федерального казначества возлагается организация и исполнение бюджетов и бюджетных средств. Указанные органы являются кассирами всех распорядителей и получателей бюджетных средств, и осуществляют платежи за счет бюджетных средств от имени и по поручению бюджетных учреждений. Данный орган исполнительной власти представляет собой централизованную систему органов, органы казначейства являются юриди-

\footnotetext{
${ }^{1}$ Болтинова О.В. Бюджетный процесс - институт бюджетного права в Российской Федерации. - М.: ООО «Издательство «Элит»»,2008. С. 189.

${ }^{2}$ Гусева T.A., Чапкович Л.E. Новая система и структура органов исполнительной власти: справ. - учебное пособие. Волтерс Клувер. 2005.С. 14-15.
}

ческими лицами и подчиняются Министерству финансов Российской Федерации.

Банковская система исполнения бюджета привела к следующим негативным последствиям:

- наблюдалась низкая оперативность в зачислении доходов, а отсутствие единой методики распределения регулирующих налогов лишало процесс управления бюджетными средствами бюджетными ресурсами оперативности;

- отсутствовала оперативная информация о полученных доходах и произведенных расходах;

- невозможность составления полноценных прогнозов, снижение эффективности управления бюджетными ресурсами вследствие дискретности исполнения бюджета, трудностей с получением оперативной информации о кассовых расходах и движении средств;

- усложнился контроль за целевым использованием бюджетных средств распорядителями кредитов, существовала возможность нецелевого использования и злоупотреблений;

- «пробег» бюджетных средств до конечных полу чателей был недопустимо долог, следствием этого являлся срыв сроков выплаты заработной платы и социально значимых выплат, что в свою очередь, приводило к росту социальной напряженности;

- сложился высокий уровень средних остатков бюджетных средств на счетах коммерческих банков ${ }^{3}$;

- подверженность бюджетных средств дополнительным рискам, потерь вследствие финансовой несостоятельности обслуживающих банков в условиях неустойчивости банковской системы;

- использование банковского плана счетов,

\footnotetext{
${ }^{3}$ Иванова Н.Г., Маковник Т.Л. Казначейская система исполнения бюджетов.2001. С. 26.
} 


\section{Финансовое право и управление - № 1 (1) • 2013}

не предусматривающего учет всей совокупности операций по исполнению бюджета и не позволяющего осуществлять эффективный бюджетный контроль ${ }^{4}$.

Так же нарушаются основные принципы обеспечения эффективности обеспечения управления процессом исполнения бюджета:

- устойчивость (из-за несвоевременности доведения до исполнителя бюджетных назначений, неподконтрольности исполнения бюджета, ненадежности связей банковской системы);

- непрерывность (из-за отсутствия механизма отслеживания всего цикла процесса исполнения бюджета, сложность проведения оперативного анализа и внесения управленческих корректировок в процессе исполнения бюджета);

- экономичность (из-за невозможности оперативного использования остатков бюджетных средств на счетах бюджетополучателей);

- прозрачность (из-за отсутствия полной, достоверной и оперативной информации об исполнении бюджета в разрезе бюджетной классификации, а также единых принципов бухгалтерского учета всех операций со средствами бюджета) $)^{5}$

Многие страны используют принцип единства кассы при исполнении бюджета в зависимости от политических и исторических условий. В Германии существует смешанная система исполнения бюджета, при которой на федеральном уровне действует банковская система, на местном - казначейская, в Испании все бюджетные средства находятся на специальном счете казначейства в Центральном банке, движение средств контролирует Генеральный

\footnotetext{
${ }^{4}$ Теребиленко Б.Н. Казначейская система: опыт и перспективы развития. М., 2004. СИП РИА. С. 12-13.

${ }^{5}$ Болтинова О.В. Бюджетный процесс - институт бюджетного права в Российской Федерации. - М.: ООО «Издательство «Элит»», 2008. С. 190-191.
}

Директорат казначейства; в Канаде за хранение денежных средств отвечает Управление главного аудитора, в то время как Казначейство контролирует распределение средств на реализацию политических программ; Канцлер Казначейства в Великобритании осуществляет надзорную деятельность за поступлениями в Консолидированный фонд - специальный счет Казначейства в Банке Англии ${ }^{6}$. «В Швеции каждому государственному госучреждению открыто определенное число банковских счетов в государственной системе единого казначейского счета, и учреждение имеет к ним прямой доступ. Однако на таких счетах никогда не хранятся ликвидные средства, выплаты производятся и регистрируются через счета учреждений, но снимаются с основного счета бюджета» ${ }^{7}$.

Наиболее приближенной к российской системе исполнения бюджета является французская система, при которой все государственные средства находятся на едином счете Казначейства, открытом в Центральном банке ${ }^{8}$.

Для того чтобы понять содержание принципа единство кассы, необходимо начать с того, что в науке финансового права известно централизованное и децентрализованное кассовое устройство ${ }^{\circ}$.

\footnotetext{
${ }^{6}$ См.: Финансовое право учебник / под. ред О.H. Горбуновой, Е.Ю. Грачевой, М., 2003. С. 429-432; ТерМинасян $T$. Создание казначейства в странах с переходной экономикой / T Тер-Минасян, П. Паренте, П. Мартинес-Мендес. - М.: 1995; Бюджетный процесс в зарубежных странах: сб. обзоров/ под ред Макаиева. M.: 1997. - C. 20-24

${ }^{7}$ Комягин Д.Л. Принцип единства кассы: опыт сравнительно-правового исследования // Козырин A.Н.Административное и финансовое право. 2006 (1). Ежегодник Центра публличных исследований, АНО ЦППИ. 2006. С. 90.

${ }^{8}$ Прокофьев С.Е. Казначейская система исполнения бюджета // Прокофьев Е.С. Бюджет 2003, июнь. С. 58.

9 Финансовое право: учебник / A.P. Батяева, К.C. Бельский, ТА. Вериило и др.; отв. ред. С.В. Запольский. 2-е изд.., испр. и доп.. - М.: Волтерс Клувер, 2011. - С. 76.
} 
И.Х. Озеровым движение от децентрализованного способа исполнения бюджета к централизованному понималось как восходящее, имеющее три этапа ${ }^{10}$. Первый этап характеризуется тем, что кассы по сбору доходов и совершению расходов созданы по отдельным ведомствам, вторым этапом яаляется централизация всех касс в руках одного ведомства - Министерства финансов, а третий, наиболее совершенный, этап является не чем иным, как создание банковской системы государственных касс.

В.А. Лебедевым отмечено, что важнейший теоретический вопрос относительно касс - это и есть вопрос о системе их централизации или единства кассы. Единство кассы заключается в том, что все государственные суммы стекаются в кассы, подведомственные Министерству финансов, что дает возможность быстро узнать, сколько имеется средств в наличии в казне государства, а это «много содействует безостановочному удовлетворению расходов». Замедление платежей, связанное с централизацией касс, «неважно в сравнении я ясностью и правильностью всего денежного движения, обеспечиваваемого единством кассы» ${ }^{11}$. В современных условиях совершенствования информационных технологий замедление платежей, носит незначительный характер.

Дефиниция принципа единства кассы в российском законодательстве установлена в ст. 216 Бюджетного кодекса Российской Федерации, в соответствии с которой принцип единства кассы предусматривает зачисление всех поступающих доходов бюджета, привлечение и погашение источников финансирование дефицита бюджета и осуществление всех расходов с единого счета бюджета

\footnotetext{
10 Там же.

11 Вострикова Л.Г. Финансовое право.: Учебник для вузов / 3-е изд. перераб. и доп. - М.: Юстицинфром. 2007. C. 64.
}

При этом в соответствии со ст. 243 БК РФ запрещается совершение операций со средствами федерального бюджета, минуя систему балансовых счетов Федерального казначейства, которые согласно ст. 244 БК РФ могут быть открыты только в Банке России. Статьей 155 БК РФ установлено, что счета бюджетов обслуживает Банк России.

Статьей 215.1 БК РФ установлено, что кассовое обслуживание исполнения бюджетов всех уровней бюджетной системы Российской Федерации осуществляется Федеральным казначейством, что является составной частью реализации принципа бюджетной системы Российской Федерации - единства бюджетной системы.

В настоящий момент принцип единства кассы существует в виде принципа единого счета. Следует отметить, что принцип единого счета, более высокая ступень развития принципа единства кассы. В этой связи представляется очень точным замечание М.И. Боголепова о том, что «центральные эмиссионные банки появились тогода, когда система казначейств и связанные с ней организации счетоводства и контроля были уже совершенно развиты и упрочены, как, например, система казначейства во Франции, которая насчитывает за собой более чем 400 - летную историю, а «Банк де Франс» был организован только в начале XIX столетия...» ${ }^{12}$. В России же исполнение бюджета первоначально именовалось кассовым устройством, эвалюция исполнения государственного бюджета в России, была тесно связана с историческими процессами происходящими в стране.

В 1992-1993 годах были приняты документы, с которых началось возраждение деятельности казначейства в России: Указ Президента Российской Федерации от 8 декабря 1992

\footnotetext{
12 Бюджетное право: учебник / A.Е. Абрамова,И.И. Кучеров, М.А. Моисеенко и др.; под. ред. Н.А. Саттаровой. - М.: Деловой двор, 2009. С. 21.
} 


\section{Финансовое право и управление - № 1 (1) • 2013}

года № 1556 «О Федеральном казначействе» ${ }^{13}$ и Постановление Правительства РФ от 27 августа 1993 г. № 864 «О федеральном казначействе Российской Федерации» ${ }^{14}$. В настоящее время основными нормативными документами, регламентирующими деятельность Федерального казначейства являются: Бюджетный кодекс Российской Федерации, Постановление Правительства от 1 декабря 2004 г. № 703 «О федеральном казначействе», акты Министерства финансов Российской Федерации, акты Федерального казначейства и другие нормативно-правовые акты.

Для эффективного управления государственными финансами казначейство имеет единый счет, по которому проводится все операции органов государственного управления и на котором консодируются все государственные ресурсы. При этом государственные финансы менее всего подвержены влиянию экономических кризисов, так как единый счет органов Федерального казначества открыт в Центральном Банке Российской Федерации. Введение единого счета было предусмотрено федеральной программой развития органов федерального казначейства на 2000-2004 г.г.

В соответствии со ст. 6 БК РФ кассовое обслуживание исполнения бюджета - проведение и учет операций по кассовым поступлениям в бюджет и кассовым выплатам из бюджета.

В соответствии со ст. 241.1 БК РФ при кассовом обслуживании исполнения бюджетов:

\footnotetext{
${ }_{13}^{13}$ Указ Президента РФ от 08.12.1992 № 1556 «О федеральном казначействе» // Утратил силу с 1 января 2005 года в связи с изданием Указа Президента РФ от 23.02.2005 № 202 // Собрание актов Президента и Правительства Российской Федерации. 1992. № 24.Ст. 2101.

${ }^{14}$ Постановление Правительства РФ от 27.08.1993 № 864 (ред. от 28.01.1997) «О Федеральном казначействе Российской Федерации» // Утратил силу с 1 января 2005 года в связи с изданием Постановления Правительства РФ от 01.12.2004 № 703 // Собрание актов Президента и Правительства Российской Федерации. 1993. № 35. Ст. 3320 .
}

- у учет операций со средствами бюджетов осущствляется на единых счетах бюджетов, открытых в соответствии с БК РФ органам Федерального Казначейства отдельно для каждого бюджета в учреждениях Центрального банка Российской Федерации;

- у управление средствами на единых счетах бюджетов осуществляют финансовые органы или иные уполномоченные органы в соотвествтвии с нормативными правовыми актами Российской Федерации, субъектов Российской Федерации, муниципальными правовоми актами;

- кассовые выплаты из бюджета осуществляются органом Федерального казначейства на основании платежных документов, представленных в орган Федерального казначейства, в порядке очередности их представления и в пределах фактического наличеия остатка средств на едином счете бюджета;

- $\quad$ все операции по кассовым поступлениям в бюджет и кассовым выплатам из бюджета на едином счете бюджета проводятся и учитываются органом Федерального казначейства по кодам бюджетной классификации Российской Федерации;

- органы Федерального казначейства представляют финансовым органам информацию о кассовых операциях по исполнению соответствующих бюджетов, а также информацию о кассовых операциях по исполнению иных бюджетов, входящих в консолидированный бюджет соответствующей территории

Кассовое обслуживание исполнения федерального бюджета является одним из основных направлений деятельности федерального Казначейства, именно там происходят постоянные изменения, связанные с разработкой и внедрением элементов управления ликвидностью единого счета федерального бюджета. 
Целью такой работы является создание условий для более качественного и эффективного управления бюджетными средствами, направленного на обеспечение безусловного исполнения денежных обязательств федерального бюджета по мере наступления сроков платежей.

Ликвидность бюджетного счета можно определить как способность в определенный момент финансового года произвести своевременную оплату денежных обязательств федерального бюджета.

Переход к управлению ликвидностью единого счета федерального бюджета, направленный на совершенствование процессов и процедур управления денежными средствами позволяет применять механизм краткосрочного заимствования денежных средств на финансовом рынке. Внедрение такого механизма дает возможность усовершенствовать процесс управления государственным долгом.

Избыток денежных средств характеризуется наличием на едином счете федерального бюджета временно свободных денежных средств, образовавшихся вследствие разницы в сроках и объемах поступлений в федеральный бюджет и осуществления выплат с единого счета федерального бюджета. В таком случае в федеральный бюджет могут поступить дополнительные расходы за счет размещения временно свободных денежных средств на финансовом рынке в виде банковских депозитов или передачи их в доверительное управление.

Зарубежный опыт показывает, что управление ликвидностью объединяет в себе вышеуказанные возможности - обеспечения необходимого минимального уровня на едином счете и получения дополнительных расходов бюджета за счет размещения временно свободных остатков средств, а также позволяет контролировать риски. Во многих экономически развитых странах помимо казначейств существуют специализированные организации, отвечающие непосредственно за управление ликвидностью единого счета и управление государственным долгом.

Например, в Финляндии существует финансовый департамент. Основными задачами финансового департамента Государственного казначейства Финляндии являются управление государственным долгом и текущей ликвидностью, выдачей кредитов муниципалитетам. На уровне директора финансового департамента принимаются решения о размещении излишков денежных средств или привлечении средств в случае дефицита бюджета. Процесс составления кассового плана автоматизирован, министерства и подведомственные ему учреждения направляют свои заявки в электронном виде в Государственное казначейство ${ }^{15}$.

Внедрение механизма управления ликвидностью позволяет в конечном итоге экономить государственные средства и снижать управленческие затраты в процессе исполнения бюджета.

Принимая во внимание сложившиюся практику кассового обслуживания исполнения федерального бюджета, структуру единого счета федерального бюджета и особенности действующего бюджетного законодательства, переход к управлению ликвидностью единого счета федерального бюджета возможно осуществить по следующим направлениям, например внедрение процедур финансового прогнозирования и кассового планировавания в процессе исполнения федерального бюджета; совершенствание и развитие процедур управления денежными средствами федерального бюджета; а также совершенствание процессов управления государственным долгом.

Современный правовой статус Федерального казначейства, определяемый бюджетным законодательством позволяет утверждать о

\footnotetext{
${ }^{15}$ Нуббина Л. Казначество Финляндии: структура, функции, задачи. / Л. ІІУбина // Бюджет. 2009. № 11. С. 35-37.
} 


\section{Финансовое право и управление - № 1 (1) • 2013}

переходе от банковской системы исполнения бюджета к казначейской. Однако считать сложившуюся систему исполнения бюджета полностью казначейской не совсем точно, поскольку она носит смешанный характер, когда техническое исполнение (осуществление расходования бюджетных средств) осуществляется Центральным банком Российской Федерации, а документарное (учет поступающих и расходуемых средств, учет получателей бюджетных средств, составление бюджетной росписи, доведение показателей росписи до распорядителей и получателей бюджетных средств в форме уведомления о лимитах бюджетных обязательств, распоряжения о перечислении бюджетных средств) - Федеральным казначейством.

Стоит ли стремится к казначейской системе исполнения бюджета, при котором Федеральное казначейство примет на себя функции по обслуживанию счетов бюджетов, ни прибегая к услугам Центрального Банка Российской Федерации при совершении транзакций со средствами бюджета бюджетной системы, на данный момент этот вопрос носит дискуссионный характер.

Федеральное казначейство является эффективной системой осуществления платежей и контроля за движением средств бюджетов бюджетной системы Российской Федерации.

Реализация процессуальных правоотношений в сфере кассового исполнения бюджета — это деятельность по регистрации всех операций, связанных с поступлением в федеральный бюджет доходов и других средств из источников финансирования дефицита федерального бюджета, а также с санкционированием и финансированием расходов федерального бюджета16. Все указанные опрерации производятся с использованием единого счета бюджета (ст. 216 БК РФ). Такая деятельность представляет

${ }^{16}$ См.: Финансовое право: учебник / отв. ред. Н.И. Химичева. М., 2012. - С. 224. собой кассовое обслуживание бюджета.

Одной из основных функций, выполняемой органами Федерального казначейства, сегодня является учет поступлений в бюджетную систему и распределение этих поступлений по соответствующим бюджетам бюджетной системы.

\section{Библиография}

1. Болтинова О.В. Бюджетный процесс институт бюджетного права в Российской Федерации.-М.: ООО «Издательство «Элит»)»,2008.

2. Бюджетное право: учебник / A.Е. Абрамова,И.И. Кучеров, М.А. Моисеенко и др.; под. ред. Н.А. Саттаровой.-М.: Деловой двор, 2009.

3. Бюджетный процесс в зарубежных странах: сб. обзоров/ под ред Макашева. М.: 1997.

4. Вострикова Л.Г. Финансовое право: Учебник для вузов / 3-е изд. перераб. и доп.-М.: Юстицинфром, 2007.

5. Гусева Т.А., Чапкович Л.Е. Новая система и структура органов исполнительной власти: справ.-учебное пособие. Волтерс Клувер. 2005.

6. Иванова Н.Г., Маковник Т.Л. Казначейская система исполнения бюджетов. 2001.

7. Комягин Д.Л. Принцип единства кассы: опыт сравнительно-правового исследования // Козырин А.Н.Административное и финансовое право. 2006 (1). Ежегодник Центра публичных исследований, АНО ЦППИ. 2006.

8. Прокофьев С.Е. Казначейская система исполнения бюджета // Прокофьев Е.C. Бюджет 2003, июнь.

9. Теребиленко Б.Н. Казначейская система: опыт и перспективы развития. М., 2004. СИП РИА.

10. Тер-Минасян Т. Создание казначейства 
в странах с переходной экономикой / T. Тер-Минасян, П. Паренте, П. МартинесМендес.-М.: 1995.

11. Финансовое право учебник / под. ред О.Н. Горбуновой, Е.Ю. Грачевой, М., 2003.

12. Финансовое право: учебник / А.Р. Батяева, К.С. Бельский, Т.А. Вершило и др.; отв. ред. С.В. Запольский. 2-е изд.., испр. и доп..-М.: Волтерс Клувер, 2011.

13. Финансовое право: учебник / отв. ред. Н.И. Химичева. М., 2012.

14. Шубина Л. Казначество Финляндии: структура, функции, задачи. / Л. Шубина // Бюджет. 2009. № 11.

\section{References (transliteration):}

1. Boltinova O.V. Byudzhetnyi protsess institut byudzhetnogo prava $\mathrm{v}$ Rossiiskoi Federatsii.-M.: OOO «Izdatel'stvo «Elit»»),2008.

2. Byudzhetnoe pravo: uchebnik / A.E. Abramova,I.I. Kucherov, M.A. Moiseenko i dr.; pod. red. N.A. Sattarovoi.-M.: Delovoi dvor, 2009.

3. Byudzhetnyi protsess v zarubezhnykh stranakh: sb. obzorov/ pod red Makasheva. M.: 1997.

4. Vostrikova L.G. Finansovoe pravo.: Uchebnik dlya vuzov / 3-e izd. pererab. i dop.-M.: Yustitsinfrom, 2007.
5. Guseva T.A., Chapkovich L.E. Novaya sistema i struktura organov ispolnitel'noi vlasti: sprav.uchebnoe posobie. Volters Kluver. 2005.

6. Ivanova N.G., Makovnik T.L. Kaznacheiskaya sistema ispolneniya byudzhetov.2001.

7. Komyagin D.L. Printsip edinstva kassy: opyt sravnitel'no-pravovogo issledovaniya // Kozyrin A.N.Administrativnoe i finansovoe pravo. 2006 (1). Ezhegodnik Tsentra publichnykh issledovanii, ANO TsPPI. 2006.

8. Prokof'ev S.E. Kaznacheiskaya sistema ispolneniya byudzheta // Prokof'ev E.S. Byudzhet 2003, iyun'.

9. Terebilenko B.N. Kaznacheiskaya sistema: opyt i perspektivy razvitiya. M., 2004. SIP RIA

10. Ter-Minasyan T. Sozdanie kaznacheistva V stranakh s perekhodnoi ekonomikoi / T. Ter-Minasyan, P. Parente, P. MartinesMendes.-M.: 1995.

11. Finansovoe pravo uchebnik / pod. red O.N. Gorbunovoi, E.Yu. Grachevoi, M., 2003

12. Finansovoe pravo: uchebnik/A.R. Batyaeva, K.S. Bel'skii, T.A. Vershilo i dr.; otv. red. S.V. Zapol'skii. 2-e izd.., ispr. i dop..-M.: Volters Kluver, 2011.

13. Finansovoe pravo: uchebnik / otv. red. N.I. Khimicheva. M., 2012.

14. Shubina L. Kaznachestvo Finlyandii: struktura, funktsii, zadachi. / L. Shubina // Byudzhet. 2009. № 11. 